\begin{tabular}{|c|c|}
\hline Title & $\begin{array}{l}\text { Direct Electrospinning of Cellulose A cetate onto Polyurethane Sheet and Effect of Its Saponification on Mechanical } \\
\text { Properties }\end{array}$ \\
\hline Author(s) & A li, Md. Momotaz; Pakkang, Nutthira; Taira, Shogo; Koda, Keiichi; Itoyama, Koki; U raki, Y asumitsu \\
\hline Citation & $\begin{array}{l}\text { Journal of wood chemistry and technology, 39(4), 282-295 } \\
\text { https://doi.org/10.1080/02773813.2019.1590416 }\end{array}$ \\
\hline Issue Date & $2019-05-25$ \\
\hline Doc URL & http:/hdl.handle.net/2115/78824 \\
\hline Rights & $\begin{array}{l}\text { This is an A ccepted Manuscript of an article published by Taylor \& Francis in Journal of Wood Chemistry and } \\
\text { Technology on } 25 \text { May 2019, available online: http://www.tandfonline.com/10.1080/02773813.2019.1590416 }\end{array}$ \\
\hline Type & article (author version) \\
\hline Additional Information & There are other files related to this item in HUSCAP. Check the above URL. \\
\hline File Information & TEXT for re submission 2.pdf \\
\hline
\end{tabular}

Instructions for use 


\section{Direct Electrospinning of Cellulose Acetate onto Polyurethane Sheet and Effect of Its Saponification on Mechanical Properties}

\section{Md. Momotaz Ali ${ }^{1}$, Nutthira Pakkang ${ }^{1}$, Shogo Taira ${ }^{1}$, Keiichi Koda ${ }^{2}$, Koki}

\section{Itoyama $^{3}$, Yasumitsu Uraki ${ }^{2 *}$}

${ }^{1}$ Graduate School of Agriculture, Hokkaido University, Sapporo 060-8589, Japan

${ }^{2}$ Research Facultyof Agriculture, Hokkaido University, Sapporo 060-8589, Japan

${ }^{3}$ Fujibo Ehime Co. Ltd., Saijo 799-1342, Japan

*Corresponding author: Yasumitsu Uraki, e-mail: uraki@for.agr.hokudai.ac.jp.

Phone: +81 011706 2817, Fax: +81 0117062817.

\section{Abstract}

This paper demonstrates direct electrospinning of two kinds of cellulose acetate, water-soluble cellulose acetate (WSCA) and cellulose diacetate (CDA), onto a non-conductive synthetic polymer sheet to modify its surface morphology. Polyurethane (PU) sheets for polishing compact and hard disks were used as an example of synthetic polymer sheet. The direct electrospinning of WSCA 11 wt.\% in aqueous ethanol solution (40 wt.\%) and CDA 9 wt.\% in aqueous acetone solution (90 wt.\%), were carried out by spraying anti-static agent onto the sheet. However, the electrospun fibers were easily peeled off from the PU sheet. Tight fixation of the fibers was achieved by spraying a 50 wt.\% of dimethylformamide/ethanol solution additionally during the spinning. Finally, the cellulose acetate fibers on the PU sheet were converted to regenerated cellulose fibers by leaving the fibers in an ammonia atmosphere for complete saponification. Change in surface morphology was evaluated by tribology test in addition to microscopic observations. Friction coefficient of PU sheet was dramatically decreased with increasing the amount of WSCA and CDA fibers deposited, suggesting that the PU sheet surface became smoother. Most of friction coefficients of the sheet were slightly increased by saponification, except for that of the PU sheet with increased amount of WSCA fibers, which might be attributed to the change in the elasticity upon saponification.

Keywords: Electrospinning • Cellulose acetate · Surface modification · Saponification. Regenerated cellulose · Tribology test 
Introduction

Cellulosic materials, cellulose nanofiber (CNF) (Yano et al., 2005; Ito, 2013; Kakroodi et al., 2014; Wang et al., 2014), and other cellulosics including cellulose derivatives (Sugimura et al., 2013; Lee et al., 2014; Sugimura et al. 2015; Li et al., 2018) have drawn much attention as a filler for plastics (Sakakibara et al., 2017), because they have much higher specific elastic modulus than steel (Nogi et al., 2009; Orts et al., 2005). In general, CNF has cellulose I crystalline polymorph. The elastic modulus of the crystalline region in cellulose I is reported to be around $135 \mathrm{GPa}$

42 (Sakurada et al.1962; Nishino et al.1995; Matsuo et al.1990). Regenerated cellulose shows 43 cellulose II polymorph (Wang et al. 2014; Sarko \& Muggli 1973) whose elastic modulus is also reported to be about 110 GPa by X-ray diffraction analysis (Matsuo et al.1990) and about $160 \mathrm{GPa}$ by theoretical estimation (Tashiro \& Kobayashi 1991). Such elastic moduli are also much higher than those of plastics (Sakurada et al.1964). Therefore, cellulosic materials are used as a filler (Sakakibara et al. 2017; Chupin et al. 2017) to improve the mechanical property of plastics (Yano et al., 2005; Borja et al., 2005). It is considered that the cellulosic materials can be utilized as a surface modification agent to alter the surface property of plastics, such as morphology and mechanical property.

There are two possible methods proposed; solution coating and direct deposition of solid material for the surface modification of plastics with cellulosics. The solution coating method may not bring high mechanical strength to the surface of plastics, because the regenerated material like film from the solutions normally amorphous and shows low elastic modulus. By contrast, direct deposition method using solid materials, such as fiber, would probably give the high elasticity to surface, because the deposited material, for example CNF, keeps high crystallinity and elastic modulus in this method. However, it is anticipated to be very difficult to spray CNF coating onto plastics, because CNF is generally produced as a viscous aqueous suspension like hydrogel (Abe and Yano, 2012) and a spraying machine for viscous hydrogel is not popular or rarely available. In addition, water evaporation after coating the CNF gel could also be a bottleneck, because it takes a long time. Hence, electrospinning seems to be a promising, alternative method for deposition of cellulosic materials. The electrospun mat has a higher Young's modulus than the cast film does (Subramanian et al., 2008). Thereby, if the direct electrospinning of cellulosic onto plastics is possible, this method must bring the high elasticity to plastic surface.

A concept of electrospinning was proposed in the $16^{\text {th }}$ century, and melt- (Norton and 66 Mass, 1936) and dry-electrospinning (Formhals, 1934) was patented in 1930's. Thus, 67 electrospinning is a very old technique. Besides such types of electrospinnings, wetelectrospinning is also available. In the dry-electrospinning with polymer solution, charged polymer solution flies as a jet from a nozzle to a collector by electric force together with the evaporation of solvent used (Hou et al., 2012; Bhardwaj \& Kundu, 2010). During the flying, polymer molecules are elongated and orientated by the electric force. It is, therefore, expected that

72 the regenerated electrospun fibers are crystallized (Zheng et al., 2007; Kongkhlang et al., 2008; 
volatile organic solvents, can be electrospun by this method. In 1934, electrospinning of CA was first reported (Formhais, 1934). Other researchers successfully prepared fine regenerated cellulose fibers by electrospinning of CA followed by saponification (Ok et al. 2008, Zhang et al. 2008, Huang et al. 2011, Stephen et al. 2011, Rodr1'guez et al. 2012). Although cellulose cannot be directly spun by the dry-electrospinning, electrospun fibers of cellulose can be obtained by wetelectrospinning. In the wet-electrospinning, polymer molecule in the solution is also elongated by the electric force and is regenerated in a coagulation bath with a non-solvent. Frey et. al (2008) summarized the wet-electrospinning of cellulose, where water was used as a coagulant for cellulose solutions in aqueous $\mathrm{N}$-methyl-morpholine $\mathrm{N}$-oxide solution and in lithium chloride/dimethylacetamide, and ethanol as a coagulant for cellulose solutions in 1-butyl-3methylimidazolium chloride and 1-ethyl-3-methylimidazolium benzoate. However, there is no report on melt-electrospinning of cellulosics, as far as we know.

We consider the dry-electrospinning of CA is a promising technique for direct deposition of cellulosics onto plastics. Kakunuri et al. (2017) reported that CA nanofiber was directly electrospun on nylon mesh sheet, which was placed on an iron collector, for producing air filter. We also confirmed that direct electrospinning on the mesh sheet was successful. However, there is no report on direct dry-electrospinning on non-mesh polymer sheet or film. The reason is probably attributed to non-electroconductivity of plastics. Static charge is accumulated on the plastics during the electrospinning. As a result, the voltage difference between a nozzle and plastics on the iron collector disappears, and the solution jet flies to other parts in the electrospinning system, but never arrives at the plastics on the collector. Therefore, an aim of this study is to develop a direct dry-electrospinning method of cellulosics onto plastics together with a fixation method.

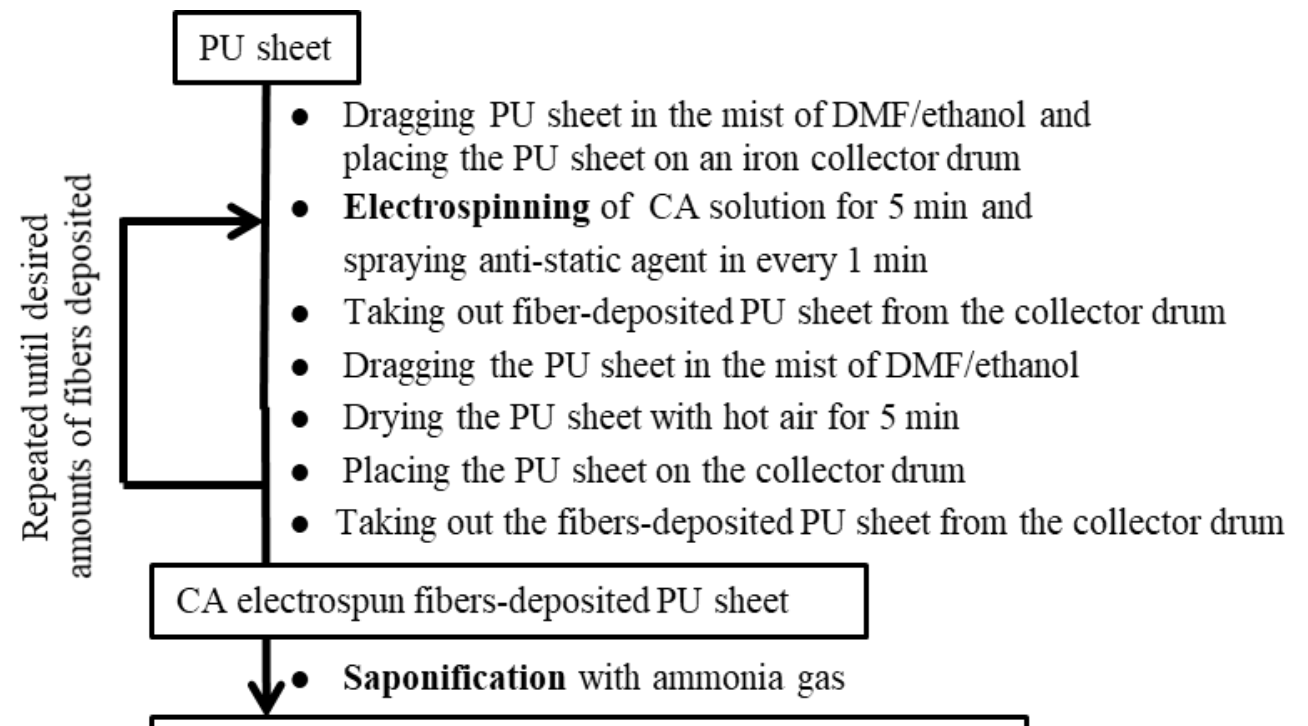

Regenerated cellulose fibers-deposited PU sheet

Fig. 1. Preparation strategy of regenerated cellulose fibers-deposited PU sheet.

To achieve the objective, we made a preparation strategy (Fig 1), which was composed of 
why the PU sheet was chosen is the ease to detect morphological change upon the electrospinning and to evaluate surface mechanical properties. Two kinds of CAs, water-soluble cellulose acetate (WSCA) and cellulose diacetate (CDA) were used as cellulosics. WSCA, which was produced as a research sample by Daicel Company (Osaka, Japan), can be dissolved in environmentally-benign solvents, such as water and aqueous ethanol. On the other hand, CDA could be dissolved in other types of solvent, such as acetone and $N, N$-dimethylformamide (DMF). Accordingly, first process is direct electrospinning of both CAs onto the PU sheet, and second process is to tightly fix electrospun fibers on the sheet. As the final process, the CA electrospun fibers are converted into regenerated cellulose by saponification to obtain fine regenerated cellulose fibers-deposited PU sheet. Change in mechanical properties of PU sheet surface by these processes is monitored by tribology test.

\section{Experiment}

\section{Materials}

Water-soluble cellulose acetate (WSCA) with a degree of substitution (DS) of 0.9 and cellulose di-acetate (CDA) with a DS of 2.4 were kindly supplied from Daicel Corporation, Ltd., (Osaka, Japan). DMF, acetone, ethanol, acetic acid and aqueous $\mathrm{NH}_{3}(28 \%)$ were purchased from Wako Pure Chemical Ltd., (Tokyo, Japan). An anti-static agent (staticide: 99.8\% of anhydrous isopropyl alcohol) was purchased from ACL Inc. (Chicago, IL, U.S.A.). Fifty to 90 wt.\% DMF/ethanol solutions were prepared. As a polishing agent for compact disc (CD) and hard disc (HD), polyurethane (PU) sheet with poly(ethylene terephthalate) (PET) as a supporting film was provided from Fujibo Ehime Co., Ltd. (Saijo, Japan) (Supplementary Figure S1). Stainless steel plate for tribology measurement was purchased from Yamamoto-MS Co., Ltd. (Tokyo, Japan).

\section{Electrospinning}

Simple electrospinning of WSCA and CDA on aluminum foil and PU sheet

WSCA was dissolved at $50{ }^{\circ} \mathrm{C}$ in 40 wt.\% aqueous ethanol solution to give its solutions at concentrations of 1-17 wt.\%. CDA was dissolved in $90 \mathrm{wt} . \%$ aqueous acetone solution to give its solutions at concentrations of 1-17 wt.\%.

The cellulose acetate (CA) solutions were inserted into a glass syringe with a stainlesssteel needle (inner diameter, $0.70 \mathrm{~mm}$ ), and then the syringe was set in an electrospinning apparatus manufactured at Machinery Laboratory, Graduate School of Science, Hokkaido University. Aluminum foil and PU sheet was separately rolled on an iron drum as a collector, after electrodes were connected to the syringe nozzle and the iron collector. When using PU sheet, the anti-static agent was sprayed onto the sheet for a few second in every 1 min during electrospinning. The syringe was pressed with a syringe pump (YMC Co., Ltd., Kyoto, Japan) at a flow rate of 1.0 $\mathrm{mL} / \mathrm{h}$. The electrospinning conditions were as follows: distance between the nozzle and the collector, $10 \mathrm{~cm}$; applied voltage, $18 \mathrm{kV}$; rotational rate of the collector, $115 \mathrm{rpm}$; spinning temperature, $30^{\circ} \mathrm{C}$; relative humidity, $22 \%$. To control the humidity and the temperature, a dehumidifier and a room heater were used during spinning.

\section{Preparation of electrospun CA fibers fixed on PU sheet}


Before spinning, a 50 wt.\% DMF/ethanol solution was sprayed in the air by using a typical sprayer, which was normally used for watering plant. An intact PU sheet $\left(115.14 \mathrm{~cm}^{2}\right)$ was dragged for $3 \mathrm{~s}$ in the solvents mist. The dragging process was repeated 3 times. The resultant PU sheet was rolled on the iron collector. Electrospinning of both CAs together with spraying the antistatic agent was carried out according to the above conditions. After 5-min electrospinning, the fiber-deposited PU sheet was taken out of the collector, and the sheet was dragged in the mist of mixed solvent followed by drying with a hair dryer for 5 min. The dried PU sheet was set again on the collector, and electrospinning was conducted again. This process was repeated until desired amount of CA fiber were deposited on the PU sheet. Finally, the fiber-deposited PU sheet was dried overnight in vacuo at $60^{\circ} \mathrm{C}$.

\section{Saponification of CA fibers}

The CA fiber-deposited PU sheet was cut into pieces (about $6 \times 3.79 \mathrm{~cm}^{2}$ ), and the resultant PU sheets were placed in a petri-dish $\left(9 \mathrm{~cm}\right.$ in diameter). About $50 \mathrm{~mL}$ of $28 \% \mathrm{NH}_{3}$ aqueous solution was poured into another petri-dish (9 $\mathrm{cm}$ in diameter). Both petri-dishes were placed in a large petri-dish (20 $\mathrm{cm}$ in diameter). Top of the large dish was covered with another large dish, and this set of petri-dishes was sealed with para-film and cooking wrap. The dish-set was left standing for one week at room temperature. The PU sheets were then taken out of the petri-dish and washed with distilled water. The PU sheets were dried in vacuo overnight at room temperature.

\section{Tribology test}

The CA fiber-deposited PU sheet with the fiber amounts of $0.81,1.61$ and $3.20 \mathrm{~g} / \mathrm{m}^{2}$ was cut into pieces (about $6 \times 3.8 \mathrm{~cm}^{2}$ ), and the resultant PU sheet was attached as a specimen with double-sided tape on an aluminum plate and then placed on a tribogear instrument (HHS3000: Shinto Science Co., Ltd, Tokyo, Japan). During the measurement, an aluminum ball as a load probe was allowed to move on the specimen under different loads. The tribology test conditions were as follows: working distance, $30 \mathrm{~mm}$; scan rate, $2 \mathrm{~mm} / \mathrm{sec}$; reciprocation times, 10; loads, 5 150 gf. The friction coefficients were calculated from the friction forces measured and the load of probe.

\section{Instrumental analysis}

The crystallinity of the CA fiber was determined using an X-ray diffractometer (Rigaku, Tokyo, Japan). Attenuated total reflection-Fourier transform infrared (ATR-FTIR) spectra of the samples were recorded with an FT/IR-4100 spectrophotometer (Jasco Co., Tokyo, Japan). The morphology of the electrospun CA fibers was observed under a 3-D microscope (violet laser color 3-D profile microscope, VK-9510: Keyence, Osaka, Japan).

\section{Results and discussion}

\section{Electrospinning of WSCA and CDA}

In this study, WSCA and CDA were used as a CA sample to prepare electrospun fibers. WSCA can be dissolved in aqueous ethanol at concentrations of 0-70 wt.\%. In the case of CDA, it was dissolved in aqueous acetone at concentrations of 60-100 wt.\%. Several spinning dopes at different CA concentrations (7, 9, 11 and 15 wt.\%) and at different concentrations of the aqueous 
organic solvents were prepared and subjected to electrospinning on an aluminum foil-covered iron collector. As a result, the electrospun fibers were able to be obtained from $11 \mathrm{wt} \%$ and higher concentrations of WSCA solutions in 40 wt.\% aqueous ethanol [Fig. 2(c)-(d)]. However, a solution of WSCA at $5 \mathrm{wt} . \%$ gave only beads, and solutions at 7, and 9 wt.\% gave beads and fibers [Fig. 2(a)-(b)]. The average dimeter of electrospun fibers was increased as an increase in WSCA concentration (Supplementary Table S1). This result was consistent with the previous findings (Amiraliyan et al. 2009, Tarus et al. 2016). Therefore, WSCA solution at 11 wt.\% in 40 wt.\% aqueous ethanol yielded the finest fibers with an average diameter of $1.20 \mu \mathrm{m}$ and smooth surface
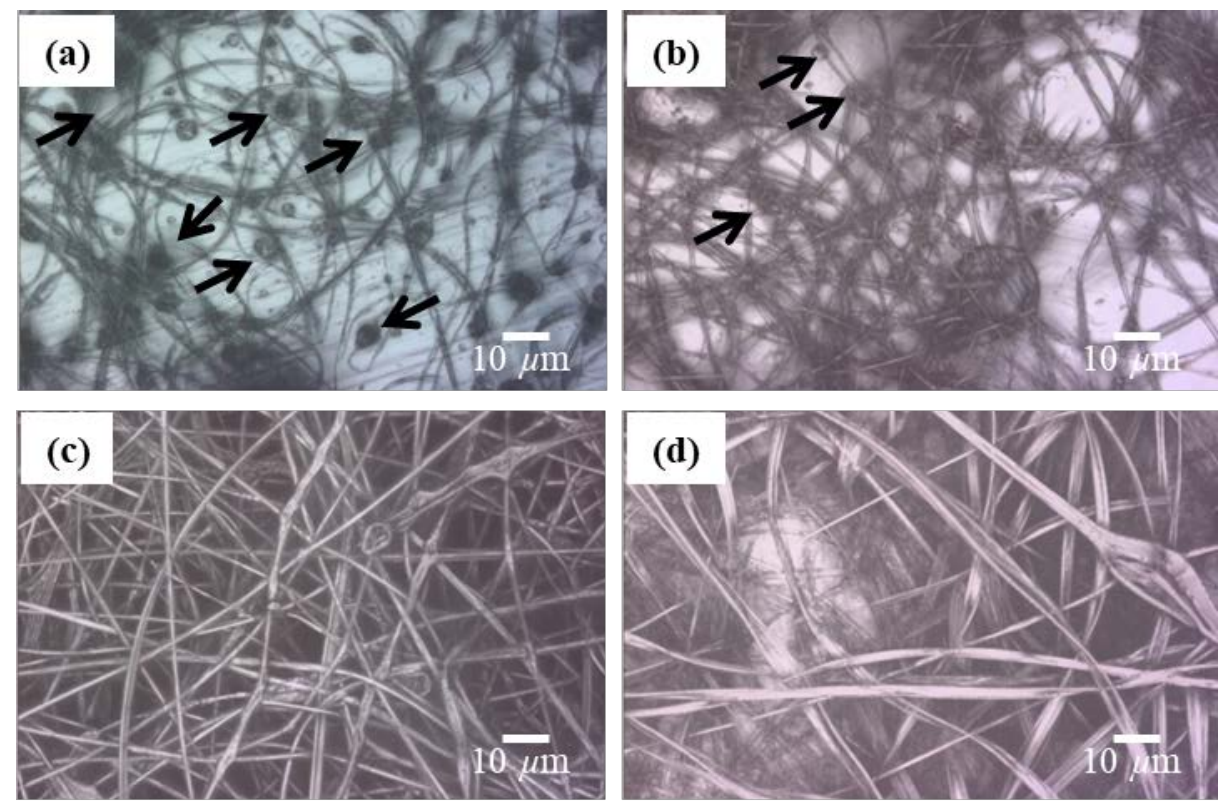

Fig. 2. Morphology of electrospun fibers at 7 wt.\% (a), 9 wt.\% (b), 11 wt.\% (c), and 15 wt.\% (d) of WSCA concentrations in 40 wt.\% ethanol solution. Arrows indicate droplets and beads.

[Fig. 2(c)], and was used for the following experiments to obtain thin fibers.

In the case of CDA, the electrospun fibers were obtained from CDA at 90 wt.\% aqueous acetone. CDA solution at $7 \mathrm{wt} \%$ concentration in the aqueous acetone gave both of fibers and
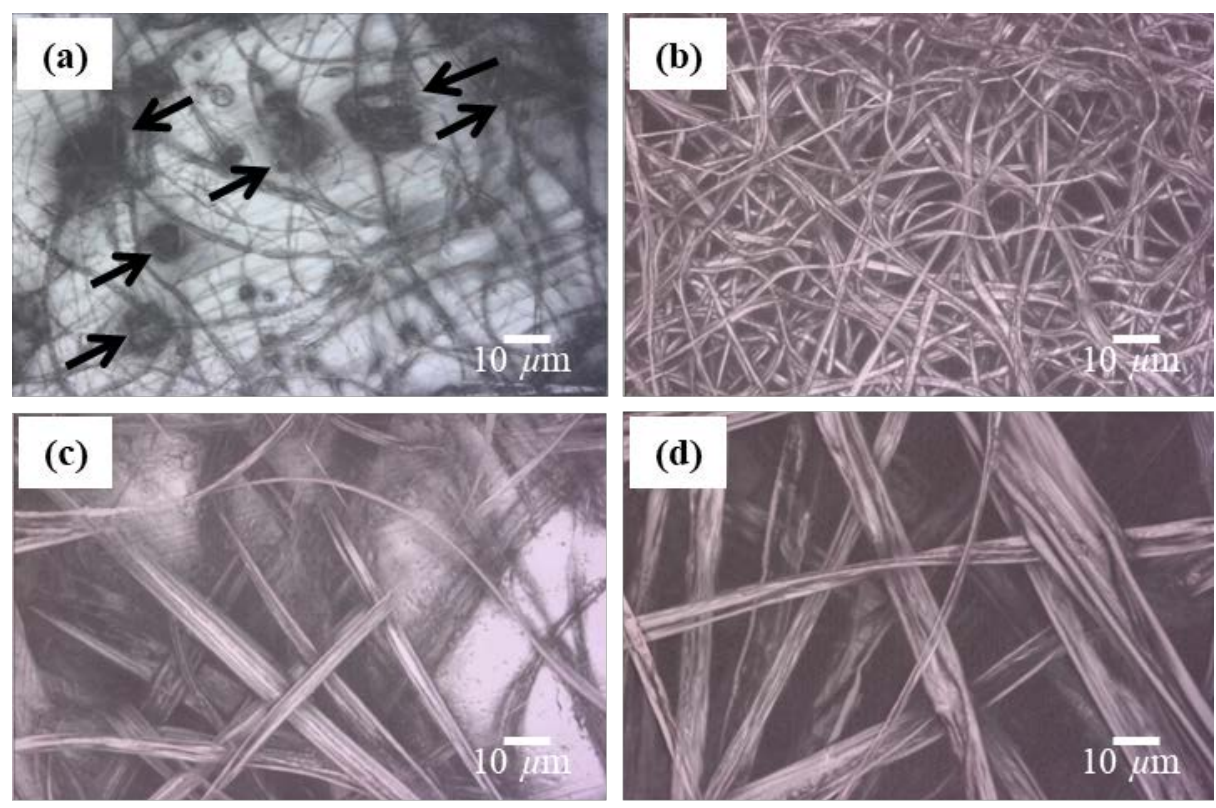

Fig. 3. Morphology of electrospun fibers at 7 wt.\% (a), 9 wt.\% (b), 11 wt. $\%$ (c), and 15 wt.\% (d) of CDA concentrations in 90 wt. $\%$ acetone solution. Arrows indicate droplets and beads. 
beads [Fig. 3(a)]. Fine fibers were obtained from the solution at 9 wt.\% and 15 wt.\% [Fig. 3(b) and (d)], respectively. CDA solution at 9 wt.\% yielded the finest fibers among the tested solutions with an average diameter of $1.69 \mu \mathrm{m}$ [Fig. 3(b)]. This solution conditions were applied to the following electrospinning experiments.

\section{Electrospinning and adhesion of CA fibers on PU sheet}

Electrospinning of WSCA and CDA on the PU sheets, which were rolled in parallel on the iron collector, was attempted using the optimized solutions of WSCA and CDA as mentioned above. Electrospun fibers were deposited on the PU sheets only for initial 2 min. Afterwards, the fibers were deposited out of the PU sheets, especially, on the non-covered surface of the iron collector between PU sheets, as shown in Fig. 4 (a) and (b). It was assumed that PU sheets were an electric insulator, and static charge was accumulated on the sheet during electrospinning, leading to unsuccessful electrospinning. To remove the static charge, anti-static agent was sprayed several times on the sheets during electrospinning. By this treatment, both CA fibers were successfully deposited on the PU sheets [Fig. 4 (c)]. This method of spraying anti-static agent was applied to other synthetic polymer sheets, such as polyethylene and poly(methylmethacrylate) sheets. As a result, this spraying method was found to be effective in direct electrospinning of CA fibers on any synthetic polymer sheet.

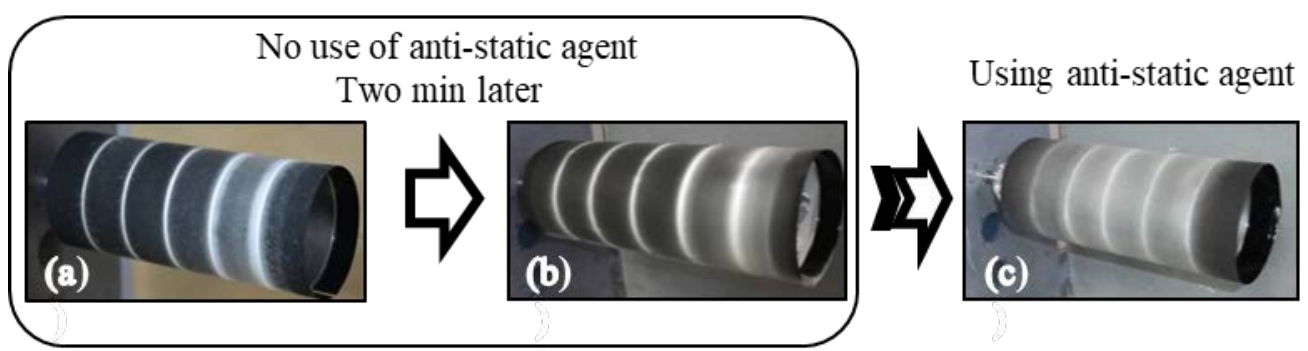

Fig. 4 Electrospun fibers deposited on PU sheet for initial 2 min (a), after 2 min (b), and with an anti-static agent (c).

However, another problem arose: the resulting electrospun CA fibers were easily peeled off from PU sheet by rubbing with a finger [Supplementary Figure S2 (a)]. To estimate the adhesion strength, fiber peeling was observed under different loads in the tribology test. The resulting electrospun CA fibers were peeled off from PU sheet under only 5 gf load [Supplementary Figure S3 (a)]. To overcome this problem, we changed a strategy for fixation of electrospun fibers on the PU sheets. DMF, as a good solvent for PU and CA, was attempted to be sprayed, in order to partly dissolve both materials to fuse them. When DMF was directly sprayed to the sheets, the electrospun fibers on PU sheets were almost dissolved to lose the fiber morphology, suggesting that DMF should be diluted. Thereby, DMF was diluted with ethanol to several concentrations, and the DMF solutions were sprayed directly on the fiber deposited PU sheet to check dissolution and adhesion of CA fibers. From this preliminary experiment, 50 wt.\% of DMF/ethanol solution was found to be a suitable solution (Supplementary Figure S4). However, this spray fixation gave rise to another problem to give a damage to PU sheet surface. To avoid the problem, the fiber-deposited PU sheets were dragged in the mist, which was prepared by spraying DMF/ethanol solution (50 wt.\%) for $1 \mathrm{sec} \times 3$ times into the air. As a result, electrospun fibers were partly fused with PU sheets (Fig. 5). Electrospun CA fibers after fixation were not peeled off easily from the 
228 [Supplementary Figures S2 (b) and S3 (b)].
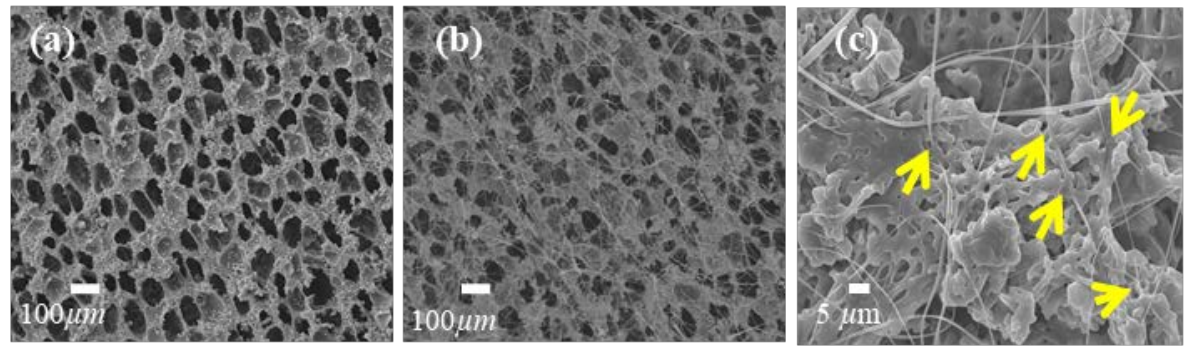

Fig. 5 SEM images of PU sheet before spinning (a), after spinning (b) and after fixation (c). Arrows indicate fused parts of CA fibers and PU sheet.

Conversion of CA to regenerated cellulose by saponification

CA was saponified with a vapor of $28 \% \mathrm{NH}_{3}$ aqueous solution to produce regenerated cellulose (Takahashi et al. 2013). The changes in the chemical structure of the CA fibers upon saponification were analyzed by using an ATR-FTIR. Since PU itself carries carbonyl groups, the carbonyl band assigned to PU and CA could not be distinguished. Therefore, completion of saponification was monitored by ATR-FTIR, using WSCA and CDA electrospun fibers deposited on aluminum foil. In Fig. 6, an ester carbonyl band at $1745 \mathrm{~cm}^{-1}$ was clearly observed in the spectra of WSCA and CDA electrospun fibers. The carbonyl band disappeared upon the saponification for $7 \mathrm{~d}$, indicating that both CAs were converted completely to regenerated cellulose.

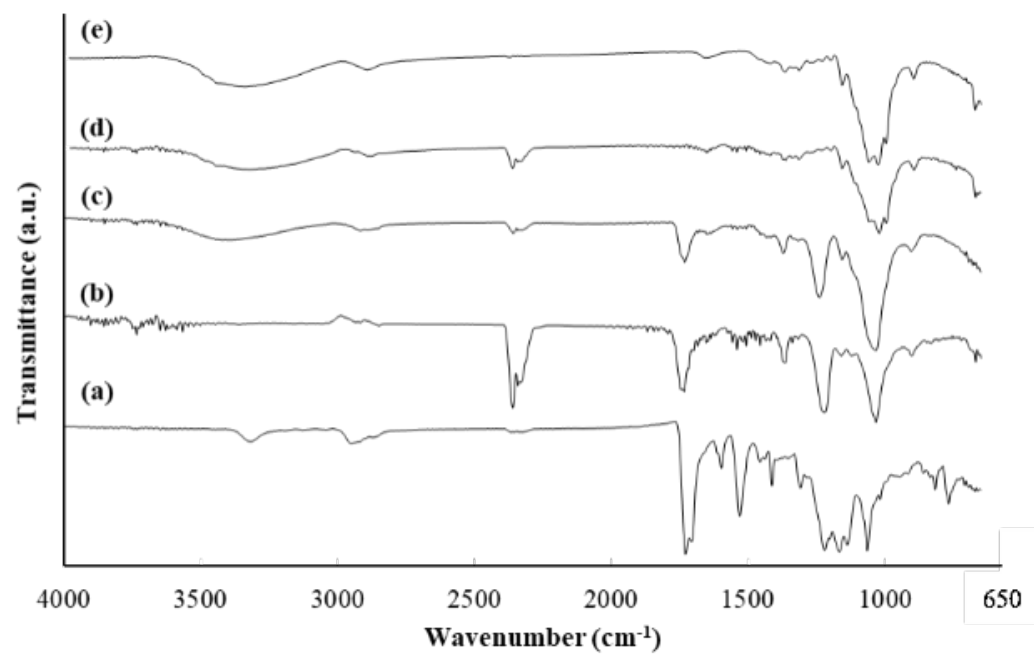

Fig.6. ATR-FTIR spectra of PU sheet (a), CDA fibers (b), WSCA fibers (c), saponified CDA fibers (d) and saponified WSCA fibers (e).

X-ray diffraction (XRD) of electrospun CA fibers before and after saponification was measured to elucidate crystalline structure (Fig. 7). Broad peaks at less than $10^{\circ}$ and at around $20^{\circ}$ were observed in unsaponified WSCA and CDA electrospun fibers [Fig. 7 (a) and (b)], indicating these fibers were amorphous. Saponified CDA fibers showed sharp peaks at $2 \theta=11.6^{\circ}, 20.1^{\circ}$, and $21.2^{\circ}$, although each intensity was not so high, suggesting a crystalline structure of cellulose II polymorph [Fig. 7 (c)]. However, saponified WSCA fibers showed peaks at $2 \theta=11.9^{\circ}$ and 20.0 where two peaks at $20.1^{\circ}$, and $21.3^{\circ}$ might be overlapped [Fig. 7 (d)]. This observation suggested 
$247 \mathrm{NH}_{3}$ vapor brought about not only deacetylation but also crystallization.

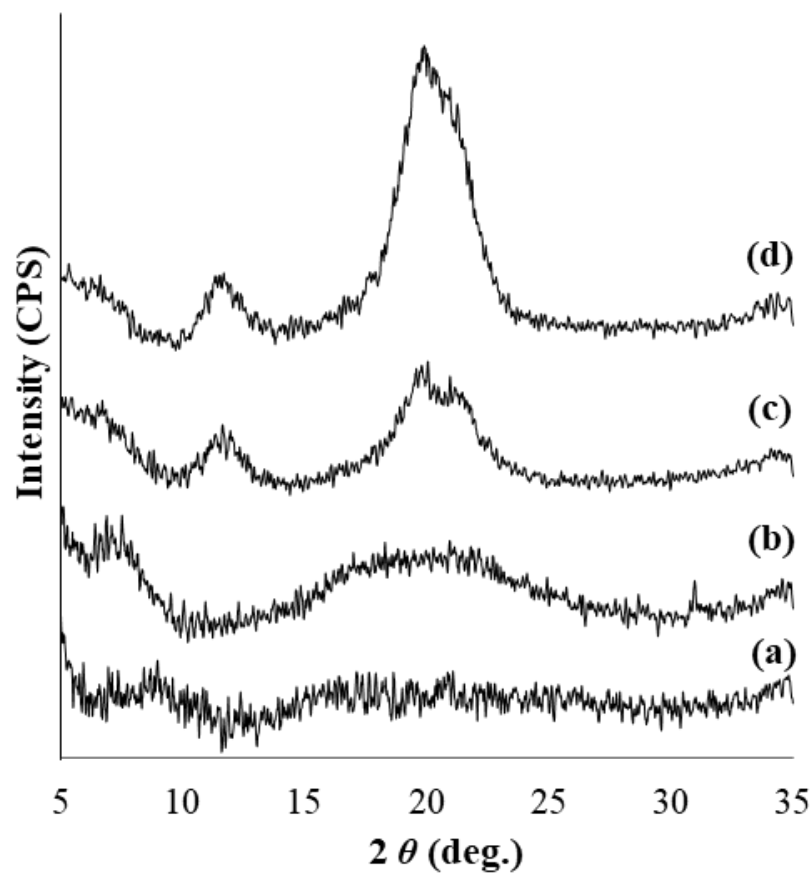

Fig.7. X-ray diffractograms of WSCA fibers (a), CDA fibers (b), regenerated cellulose from CDA fibers (c), and regenerated cellulose from WSCA fibers (d).
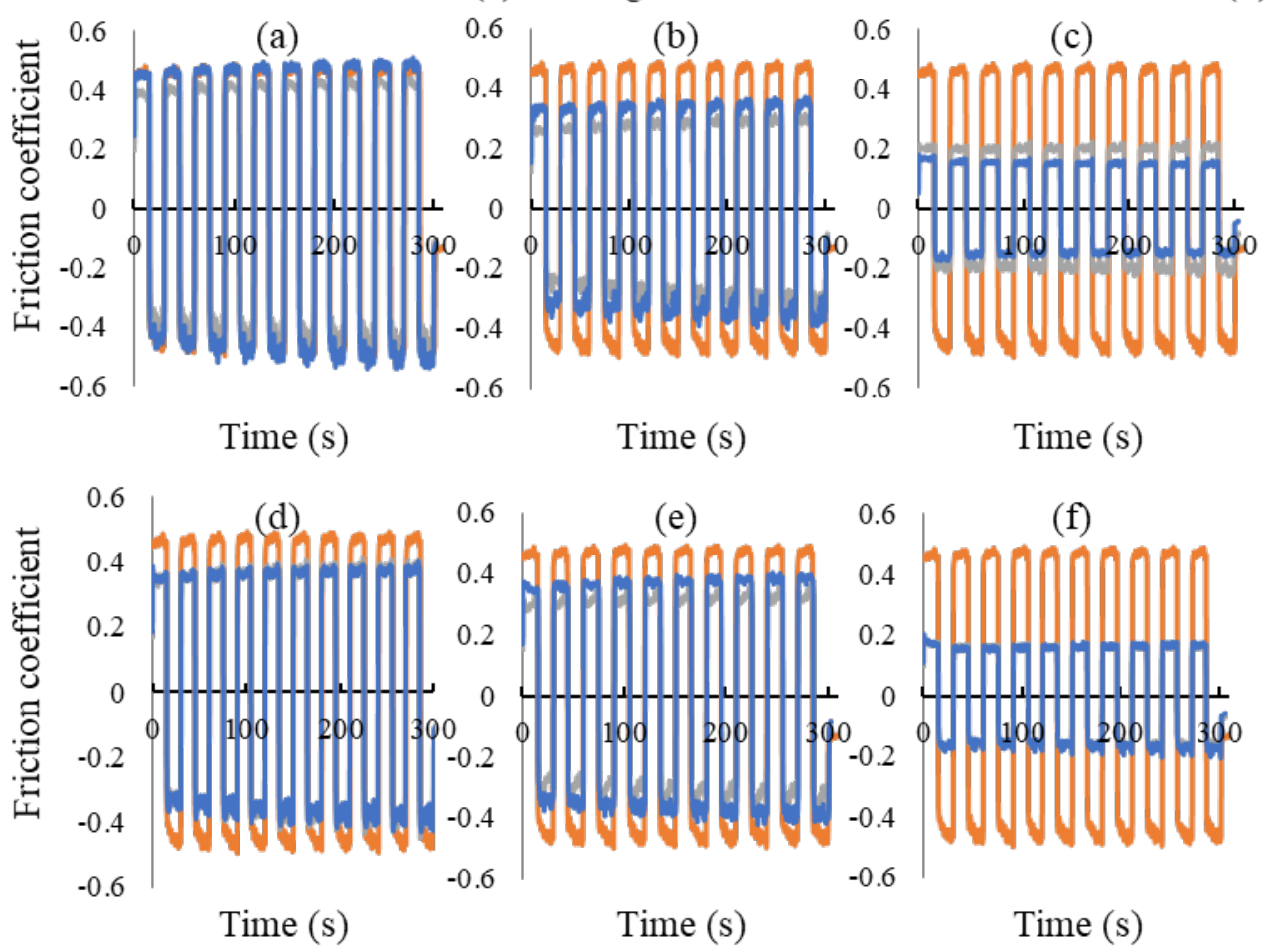

Fig. 8. Profiles of friction coefficient under a load of $150 \mathrm{gf}$ in the tribology test. (a)-(c), intact PU sheets (orange line), WSCA fibers (gray line), saponified WSCA fibers (blue line) deposited on PU sheets. (d)-(f), intact PU sheets (orange line), CDA fibers (gray line) and saponified CDA fibers (blue line) deposited on PU sheets. (a) and (d), at the deposited fiber amount of $0.81 \mathrm{~g} / \mathrm{m}^{2}$; (b) and (e), at the deposited fiber amount of $1.61 \mathrm{~g} / \mathrm{m}^{2}$; (c) and (f), at the deposited fiber amount of $3.20 \mathrm{~g} / \mathrm{m}^{2}$. 
Tribology test was carried out to evaluate the change in physical property of PU sheets upon the electrospun fibers deposition and saponification. Amounts of both WSCA and CDA electrospun fibers deposited on PU sheets were $0.81,1.61$ and $3.20 \mathrm{mg} / \mathrm{m}^{2}$. Tribology test was carried out under the loads of 50, 100, and 150 gf. Profiles of friction coefficients for CAdeposited PU sheet under the load of 150 gf in the tribology test are typically shown in Fig. 8, because other profiles under any loads were found very similar. The static $\left(\mu_{s}\right)$ and the kinetic $\left(\mu_{k}\right)$ friction coefficients are summarized in Table 1. Both coefficients of PU sheet were decreased by the deposition of WSCA and CDA fibers, and the decrement of coefficients depended on the deposited amounts of fibers. This phenomenon can be explained as follows. The friction coefficient of intact PU sheet was high probably due to the rough surface. When CA fibers were deposited on the PU sheet, the rough surface was partially covered with the fibers. As a result, the surface became flat, leading to a decrease in friction coefficients and its dependency on deposited

Table 1. Friction coefficient of intact PU sheet, CDA and WSCA electrospun fibers-deposited on PU sheet, and their saponified fibers-deposited PU sheet with varying amounts of deposited fibers under different loads $(50,100$ and 150 gf).

\begin{tabular}{|c|c|c|c|c|c|c|c|c|c|c|c|c|}
\hline \multirow{3}{*}{$\begin{array}{l}\text { Friction } \\
\text { coefficient }\end{array}$} & \multirow{3}{*}{$\begin{array}{l}\mathrm{PU} \\
\text { sheet }\end{array}$} & \multicolumn{4}{|c|}{ Fiber amount $0.81 \mathrm{mg} / \mathrm{m}^{2}$} & \multicolumn{3}{|c|}{ Fiber amount $1.61 \mathrm{mg} / \mathrm{m}^{2}$} & \multicolumn{4}{|c|}{ Fiber amount $3.20 \mathrm{mg} / \mathrm{m}^{2}$} \\
\hline & & \multicolumn{2}{|c|}{ WSCA } & \multicolumn{2}{|c|}{ CDA } & \multicolumn{2}{|c|}{ WSCA } & CDA & \multicolumn{2}{|c|}{ WSCA } & \multicolumn{2}{|c|}{$\mathrm{CDA}$} \\
\hline & & Before $^{a}$ & After ${ }^{b}$ & Before $^{a}$ & After ${ }^{b}$ & Before $^{a}$ & After ${ }^{b}$ & Before $^{\mathrm{a}}$ After $^{\mathrm{b}}$ & Before $^{\mathrm{a}}$ & After ${ }^{\mathrm{b}}$ & Before $^{a}$ & After ${ }^{b}$ \\
\hline \multicolumn{13}{|c|}{ Load : 50 gf } \\
\hline$\mu_{s}$ & 0.560 & 0.418 & 0.515 & 0.322 & 0.387 & 0.269 & 0.334 & $\begin{array}{lll}0.323 & 0.355\end{array}$ & 0.172 & 0.155 & 0.154 & 0.174 \\
\hline$\mu_{k}$ & 0.564 & 0.411 & 0.502 & 0.315 & 0.367 & 0.248 & 0.378 & $\begin{array}{lll}0.315 & 0.357\end{array}$ & 0.166 & 0.149 & 0.149 & 0.170 \\
\hline \multicolumn{13}{|c|}{ Load : 100 gf } \\
\hline$\mu_{s}$ & 0.507 & 0.430 & 0.499 & 0.370 & 0.409 & 0.290 & 0.365 & 0.3490 .391 & 0.205 & 0.154 & 0.164 & 0.181 \\
\hline$\mu_{k}$ & 0.509 & 0.423 & 0.489 & 0.352 & 0.389 & 0.275 & 0.356 & 0.3320 .371 & 0.195 & 0.147 & 0.159 & 0.176 \\
\hline \multicolumn{13}{|c|}{ Load : $150 \mathrm{gf}$} \\
\hline$\mu_{5}$ & 0.444 & 0.409 & 0.483 & 0.395 & 0.394 & 0.301 & 0.338 & 0.3420 .380 & 0.206 & 0.157 & 0.163 & 0.168 \\
\hline$\mu_{k}$ & 0.459 & 0.409 & 0.475 & 0.365 & 0.365 & 0.279 & 0.338 & 0.3160 .366 & 0.202 & 0.152 & 0.160 & 0.163 \\
\hline
\end{tabular}
amounts of fibers.

By saponification, all the friction coefficients were increased, except for those of WSCAdeposited PU sheet at the amount of $3.20 \mathrm{mg} / \mathrm{m}^{2}$. This phenomenon was explained by the change in both types of CA fiber structure from amorphous state before saponification to crystalline state after saponification, as shown in Fig. 7. The deposited crystalline fibers might have high Young's modulus or high stiffness that directly affected the friction coefficients.

In the case of saponified WSCA fibers deposited on PU sheets at 0.81 and $1.61 \mathrm{mg} / \mathrm{m}^{2}$, the friction coefficients had a similar trend to those of saponified CDA fibers, while the friction coefficients of saponified WSCA fibers at $3.20 \mathrm{mg} / \mathrm{m}^{2}$ was lower than those of non-saponified

270 ones and was the lowest among samples. Although the reason for the lowest coefficients is unclear, 271 the thickness or the diameter of the electrospun fibers may affect the friction coefficients. The saponified WSCA electrospun fibers (1.16 $\mu \mathrm{m}$ in diameter) were thinner than the corresponding

273 CDA fibers (1.73 $\mu \mathrm{m}$ in diameter). When much larger amount of fine CA fibers was deposited on 274 the PU sheet, the rough surface of the sheet was considered to be densely covered with the fibers 
to give flatter surface or to decrease surface roughness. The smaller surface roughness of the WSCA fibers $\left(3.20 \mathrm{mg} / \mathrm{m}^{2}\right)$-deposited PU sheet was confirmed by 3-D laser microscopic observation, according to ISO 4287: 1997 (Supplementary Table S2). The flatter surface would give lower resistance to the friction against an aluminum ball as a probe of this tribology measurement. Thus, the surface physical property of PU sheets was found to be dramatically altered by the deposition of WSCA and CDA electrospun fibers and their saponification.

\section{Conclusion}

Modification of surface physical property of PU sheet was attempted by direct electrospinning of WSCA and CDA solutions in this study. Fine electrospun fibers with diameters of $1.20 \mu \mathrm{m}$ and $1.69 \mu \mathrm{m}$ were be obtained from 11 wt.\% of WSCA in 40 wt.\% aqueous ethanol solution and 9 wt.\% of CDA in 90 wt.\% aqueous acetone solution, respectively. Direct electrospinning of both CA fibers on non-electroconductive PU sheets was successfully carried out by spraying an antistatic agent on PU sheet to remove the static charge. This method of spraying an anti-static agent enabled direct electrospinning of CA on any types of synthetic polymer sheet, such as polyethylene and poly(methylmethacrylate).

Although the deposited fibers on PU sheet were easily peeled off from PU sheet by finger rubbing, the fibers were tightly fixed on the sheet by dragging the fiber-deposited PU sheets in the mist of DMF/ethanol solution followed by partial fusion of the fibers with the surface of PU sheet. The WSCA and CDA electrospun fibers were saponified with $\mathrm{NH}_{3}$ vapor to yield regenerated cellulose fibers with obvious crystalline structure of cellulose II polymorph. In tribology test, the friction coefficients of electrospun CA fibers-deposited PU sheet were decreased with an increase in the amount of CA deposited. Moreover, the friction coefficients of the sheet were slightly increased by saponification, except for WSCA fibers-deposited PU sheet at $3.20 \mathrm{mg} / \mathrm{m}^{2}$. Thus, surface physical property of PU sheet was successfully altered by direct electrospinning of CAs

\section{Reference}

Abe K, Yano H (2012) Cellulose nanofiber-based hydrogels with high mechanical strength. Cellulose 19:1907-1912. https://doi.org/10.1007/s10570-012-9784-3

Amiraliyan N, Nouri M, Kish MH (2009) Electrospinning of silk nanofibers. I. An investigation of nanofiber morphology and process optimization using response surface methodology. Fiber Polym 10:167-176. https://doi.org/10.1007/s12221-009-0167-9

Bhardwaj N, Kundu SC (2010) Electrospinning: A fascinating fiber fabrication technique. Biotechnol Adv 28:325-347. https://doi.org/10.1016/j.biotechadv.2010.01.004

Borja Y, Rieß G, Lederer K (2005) Synthesis and Characterization of Polypropylene Reinforced with Cellulose I and II Fibers. J Appl Polym Sci 101:364-369. https://doi.org/10.1002/app.23847 
Budinger WD (1990) Pad material for grinding, lapping and polishing. United States Patent US 4,927,432.

Chupin L, Arnoult S, Brancourt-Hulmel M, Lapierre C, Gineau E, Navard P (2017) Polyethylene composites made from below-ground miscanthus biomass. Ind Crop Prod 109:523-528. https://doi.org/10.1016/j.indcrop.2017.09.007

Formhals A (1934) Process and apparatus for preparing artificial threads. United States Patent US $1,975,504$.

Frey MW (2008) Electrospinning cellulose and cellulose derivatives. Polym Rev 48:378-391. https://doi.10.1080/15583720802022281.

Ho JK, Huang CY, Tsai MY, Tsai CC (2016) Investigation of Polishing Pads Impregnated with Fe and $\mathrm{Al}_{2} \mathrm{O}_{3}$ Particles for Single-Crystal Silicon Carbide Wafers. Appl Sci 6:89. https://doi.org/10.3390/app6030089

Hou Z, Li G, Lian H, Lin J (2012) One-dimensional luminescent materials derived from the electrospinning process: preparation, characteristics and application. J Mater Chem 22:5254-5276. https://doi.org/10.1039/c2jm15638e

Huang XJ, Chen PC, Huang F, Ou Y, Chen MR, Xu ZK (2011) Immobilization of Candida rugosa lipase on electrospun cellulose nanofiber membrane. J Mol Catal BEnzym 70:95-100. https://doi.org/10.1016/j.molcatb.2011.02.010

Ito H (2013) Wood Plastic Composites Using Cellulose Nanofiber Technique, Nippon Gomu Kyokaishi 86:41-45. https://doi.org/10.2324/gomu.86.41

Kakroodi AR, Cheng S, Sain M, Asiri A (2014) Mechanical, thermal, and morphological properties of nanocomposites based on polyvinyl alcohol and cellulose nanofiber from Aloe vera rind. J Nanomat 2014:12-18. https://doi.org/10.1155/2014/903498

Kakunuri M, Wanasekara ND, Sharma CS, Khandelwal M, Eichhorn SJ (2017) Three-dimensional electrospun micropatterned cellulose acetate nanofiber surfaces with tunable wettability. J Appl Polym Sci 134:44709-44715. https://doi.org/10.1002/app.44709

Kongkhlang T, Tashiro K, Kotaki M, Chirachanchai S (2008) Electrospinning as a new technique to control the crystal morphology and molecular orientation of polyoxymethylene nanofibers electrospinning as a new technique to control the crystal morphology and molecular orientation of polyoxymethylene, J Am Chem Soc 12:1546015466. https://doi.org/10.1021/ja804185s

Lee S, Pan H, Hse CY, Gunasekaran AR, Shupe TF (2014) Characteristics of 
regenerated nanocellulosic fibers from cellulose dissolution in aqueous solutions for wood fiber/polypropylene composites. J Thermoplast Compos Mater 27:558-570. https://doi.org/10.1177/0892705713484739

Li Y, Wang B, Wang B, Ma M (2018) The enhancement performances of cotton stalk fiber / PVC composites by sequential two steps modification. J Appl Polym Sci 135:46090-46097. https://doi.org/10.1002/app.46090

Matsuo M, Sawatari C, Iwai Y, Ozaki F (1990) Effect of orientation distribution and crystallinity on the measurement by x-ray diffraction of the crystal lattice moduli of cellulose I and II, Macromolecules 23:3266-3275. https://doi.org/10.1021/ma00215a012

Moubarik A, Grimi N, Boussetta N (2013) Structural and thermal characterization of Moroccan sugar cane bagasse cellulose fibers and their applications as a reinforcing agent in low density polyethylene. Compos Part B: Engineering 52:233-238. https://doi.org/10.1016/j.compositesb.2013.04.040

Nicosia A, Keppler T, Müller FA, Vazquez B, Ravegnani F, Monticelli P (2016) Cellulose acetate nano fiber electrospun on nylon substrate as novel composite matrix for efficient, heat-resistant, air filters, Chem Eng Sci 153:284-294. https://doi.org/10.1016/j.ces.2016.07.017

Nishino T, Takano K, Nakamae K (1995) Elastic modulus of the crystalline regions of cellulose polymorphs. J Polym Sci, Part B: Polym Phys 33:1647-1651. https://doi.org/10.1002/polb.1995.090331110

Nogi BM, Iwamoto S, Nakagaito AN (2009) Optically Transparent Nanofiber Paper, Adv Mater 21:1595-1598. https://doi.org/10.1002/adma.200803174

Norton CL (1936). Method of and apparatus for producing fibers or filamentary material. United States Patent 2,048,651

Ok S, Ho J, Dan K, Ok Y, Ho W (2008) Electrospinning of cellulose acetate nanofibers using a mixed solvent of acetic acid /water: Effects of solvent composition on the fiber diameter, Mater Lett 62:759-762. https://doi.org/10.1016/j.matlet.2007.06.059

Orts, W. J., Shey, J., Imam, S. H., Glenn, G. M., Guttman, M. E., \& Revol, J. (2005). Application of Cellulose Microfibrils in Polymer Nanocomposites, J Polym Environ 13:301-306. https://doi.org/10.1007/s10924-005-5514-3

Rodríguez K, Gatenholm P, Renneckar S (2012) Electrospinning cellulosic nanofibers for biomedical applications: Structure and in vitro biocompatibility. Cellulose, 19:1583-1598. https://doi.org/10.1007/s10570-012-9734-0

Sakakibara K, Moriki Y, Yano H, Tsujii Y (2017) Strategy for the improvement of the mechanical properties of cellulose nano fiber-reinforced high-density polyethylene nanocomposites using diblock copolymer dispersants. ACS Appl Mater Inter 9:4407944087 
https://doi.org/10.1021/acsami.7b13963

Sakurada I, Nukushima Y, Ito T (1962) Experimental determination of the elastic modulus of crystalline regions in oriented polymers. J Polym Sci 57:651-660.

Sakurada I, Ito T, Nakamae K (1964) Elastic moduli of crystal lattices of polymers. J Polym Sci Part C 15:75-91. https://doi.org/10.1002/polc.5070150107

Sarko A, Mugglilb R (1973) Packing analysis of carbohydrates and polysaccharides. III. Vulonia Cellulose and Cellulose II, Macromolecules 7:486-494. https://doi.org/10.1021/ma60040a016

Stephen M, Catherine N, Brenda M, Andrew K, Leslie P, Corrine G (2011) Oxolane2,5-dione modified electrospun cellulose nanofibers for heavy metals adsorption. J Hazard Mater 192:922-927. https://doi.org/10.1016/j.jhazmat.2011.06.001

Subramanian A, Vu D, Larsen GF, Lin H (2005) Preparation and evaluation of the electrospun chitosan/PEO fibers for potential applications in cartilage tissue engineering. J Biomater Sci-Polym E 16:861-873. https://doi.org/10.1163/1568562054255682

Sugimura K, Teramoto Y, Nishio Y (2013) Blend miscibility of cellulose propionate with poly ( N -vinyl pyrrolidone- co -methyl methacrylate ). Carbohydr Polym 98:532-541. https://dx.doi.org/10.1016/j.carbpol.2013.06.045

Sugimura K, Teramoto Y, Nishio Y (2015) Insight into miscibility behaviour of cellulose ester blends with $\mathrm{N}$-vinyl pyrrolidone copolymers in terms of viscometric interaction parameters. Cellulose 22:2349-2363. https://doi.org/10.1007/s10570-015-0660-9

Takahashi T, Oowaki M, Onohara Y (2013) Deodorant performance of titanium dioxideadded acrylic/ cellulose diacetate blended fibers. Text Res J 83:800-812. https://doi.org/10.1177/0040517512460295

Tarus B, Fadel N, Al-Oufy A, El-Messiry M (2016) Effect of polymer concentration on the morphology and mechanical characteristics of electrospun cellulose acetate and poly (vinyl chloride) nanofiber mats. Alexandria Engineering Journal 55:2975-2984. https://dx.doi.org/10.1016/j.aej.2016.04.025

Tashiro K, Kobayashi M (1991) Theoretical evaluation of three-dimensional elastic constants of native and regenerated celluloses: role of hydrogen bonds, Polymer 32:1516-1526. https://doi.org/10.1016/0032-3861(91)90435-L

Wang H, Li D, Yano H, Abe K (2014). Preparation of tough cellulose II nanofibers with high thermal stability from wood. Cellulose 21:1505-1515. https://doi.org/10.1007/s10570-014-0222-6

Yano BH, Sugiyama J, Nakagaito AN, Nogi M, Matsuura T, Hikita M, Handa K (2005) Optically Transparent Composites Reinforced with Networks of Bacterial Nanofibers, Adv Mater 17:153-155. https://doi.org/10.1002/adma.200400597 
438 Zhang L, Menkhaus TJ, Fong H (2008) Fabrication and bioseparation studies of

439 adsorptive membranes/felts made from electrospun cellulose acetate nanofibers. J Membr

$440 \quad$ Sci 319:176-184.

$441 \quad$ https://doi.org/10.1016/j.memsci.2008.03.030

442 Zheng J, He A, Li J, Han CC (2007) Polymorphism control of poly(vinylidene fluoride)

443 through electrospinning. Macromol Rapid Comm 28:2159-2162.

444 https://doi.org/10.1002/marc.200700544 